\title{
Rock mass strength at depth and implications for pillar design
}

\author{
P.K. Kaiser Centre for Excellence in Mining Innovation, Canada \\ B. Kim MIRARCO, Laurentian University, Canada \\ R.P. Bewick Golder Associates Ltd., Canada \\ B. Valley Centre for Excellence in Mining Innovation, Canada
}

\begin{abstract}
Construction of infrastructure in deep underground mines depends on both an understanding of near wall rock behaviour as well as the ultimate load bearing capacity of confined rock, and thus on a reliable strength criterion for the rock near and far from the excavation. The topic of brittle failing rock, i.e. rock failure dominated by tensile crack and fracture propagation even under low overall compressive conditions, is briefly summarised. Recently, it was suggested that the failure envelop for the entire confinement range of brittle rocks and rock masses is distinctly s-shaped. If validated, this impacts engineering problems such as pillar design where both wall instability and confined rock mass stability issues need to be considered.

This paper explores the limitations and potential opportunities in pillar design. It is illustrated that current empirical design rules may be flawed and further studies are required to arrive at more economic designs for pillars at depth, or under high stress, and in brittle failing rock masses. When confined in the core of pillars, the rock mass may exhibit superior strength than typically assumed by Mohr-Coulomb or Hoek-Brown failure criteria as it will fail differently than near the wall. As a result, pillar strength may be underestimated based on field observations and if procedures of rock strength back-analysis from near wallbehaviour are adopted to determine the rock mass strength envelop. This means that the strength of pillars with width to height ratios $(W / H)$ exceeding 1.5 to 2 may be systematically underestimated and may become burst-prone, as the core may not yield as anticipated. Consequently, pillar designs based on current empirical rules may be inadvertently conservative and thus not optimal from an economic perspective. This aspect is of particular interest for block cave mines where drawpoint spacing may have a significant impact on cave propagation, recovery performance, and economics.
\end{abstract}

\section{Introduction}

The consideration for adopting mass mining extraction strategies at depths $>2000 \mathrm{~m}$, e.g. for deep caving operations, generates a number of challenges; one of them being infrastructure development and maintenance. One critical issue for caving operations is minimising drawpoint spacing to ensure proper ore flow and caving behaviour. Drawpoint spacing is controlled by the minimum allowable pillar width. Thus, design optimisation of these pillars relies on the ability to properly estimate the rock mass strength at depth.

Geomechanical engineers typically use rock mass classification approaches to estimate rock mass strength. These approaches are based upon experience gained at relatively shallow depths (typically $<1000 \mathrm{~m}$ ) and from observations near excavation walls. Therefore, the application of these standard approaches, to rock masses at greater depths and for estimating the strength in pillar cores, could be flawed and lead to costly mistakes.

Rock mass strength as estimated from classification systems such as by the GSI approach (Hoek et al., 2002), were calibrated by observations of the rock mass response near underground openings where the confinement drops to low values near the boundary. There are indications that the degradation rate from intact to rock mass strength is not independent of confinement (Kaiser and Kim, 2008; Kaiser, 2010). Hence, the degradation factors $\left(C_{s}\right.$ and $C_{m}$, (Kaiser and Kim, 2008)) under high confinement, may be higher than those obtained from calibrations at low confinement and the rock masses under confinement may be significantly stronger than anticipated using conventional approaches. If this hypothesis holds, the consequences or potential opportunities for mine design optimisation at depth are considerable. 
This paper is motivated by the hypothesis that rock mass strength under confinement is higher than that derived from standard approaches. Details are provided on an alternate approach to obtain the s-shaped failure criterion for the rock mass, called the modified s-shaped criterion, as well as approaches to take this failure criterion into account in numerical stress modelling and design. The impact of the s-shaped failure envelop on pillar design is highlighted.

The authors wish to point out that parts of this paper are of speculative nature and required further field verification. Nevertheless, the concept and rationale are presented here to: a) create an awareness of potential conservatism in pillar design; b) to warn designers regarding the use of overly simplistic empirical approaches and from results produced by standard failure criteria; c) to lay the foundation for future data collection to assist in the development of advanced pillar design approaches.

\section{Strength of brittle failing rock masses}

The practical estimation of rock mass strength commonly includes rock mass classification and empirical relationships. These approaches allow the derivation of equivalent continuous and homogenous rock mass properties, which intrinsically are discontinuous and heterogeneous, for modelling using continuum approximations. In these methods, the intact strength is reduced as a function of rock mass characteristics such as block size, joint conditions, etc. In other words, the intact rock strength is degraded to obtain an equivalent rock mass strength, here referred to as rock mass strength degradation. In the GSI classification system, this degradation is reflected in Equations (2) to (4) by the constants $C_{s}$ and $C_{m}$ to arrive at the strength parameters for the generalised Hoek-Brown failure criterion for jointed rock masses (Equation (1)) (Hoek and Brown, 1997; Hoek et al., 2002). The following empirical equation for the rock mass is obtained by degrading the intact rock strength such that the general shape of the strength envelop is maintained.

$$
\sigma_{1}^{\prime}=\sigma_{3}^{\prime}+\sigma_{c i}\left(m_{b} \frac{\sigma_{3}^{\prime}}{\sigma_{c i}}+s\right)^{a}
$$

where $\sigma_{1}{ }^{\prime}$ and $\sigma_{3}$ ' are the maximum and minimum effective principal stresses at failure and $\sigma_{\mathrm{ci}}$ is the uniaxial compressive strength of the intact rock; $m_{b}, s$ and $a$ are functions of GSI (with GSI ranging from 100 for massive rock, to $\sim 60$ for moderately jointed, to much lower values for very poor quality rock masses) and determined empirically based on the following equations:

$$
\begin{gathered}
s=\exp \left(\frac{G S I-100}{C_{s}}\right) \\
m_{b}=m_{i} \exp \left(\frac{G S I-100}{C_{m}}\right) \\
a=\frac{1}{2}+\frac{1}{6}\left[\exp \left(-\frac{G S I}{15}\right)-\exp \left(-\frac{20}{3}\right)\right]
\end{gathered}
$$

where $C_{s}$ and $C_{m}$ are empirical constants controlling the rate of degradation of the strength envelop from intact rock to rock mass properties (typically $C_{s}=9$ and $C_{m}=28$ ). The resulting failure envelop in the principal stress space is presented on Figure 1a for a constant rate of degradation, i.e. the rate of degradation is identical at low and high confinement. As a consequence, the strength reduction is larger in absolute terms when highly confined (fanning of the curves toward high confinement on Figure 1a).

The degradation approach of Hoek et al. (2002) presented in Equations (1) to (4) and Figure 1a is empirical and is valid only within the limits of the supporting dataset. Since little to no data is available for confined rock mass failure, the constant rock mass strength degradation approach could be flawed, particularly in relatively highly confined pillar cores of massive to moderately jointed rock, because:

1. The degradation constants $\left(C_{s}\right.$ and $\left.C_{m}\right)$ were primarily determined from back-analyses of tunnels with GSI $<65$ and therefore may not be applicable for brittle rock masses with GSI $>65$.

2. The degradation constants were established to obtain appropriate rock mass parameters for support design and simulation of instability processes near excavations in the low confinement zone and therefore they may not be applicable for confined rock. 


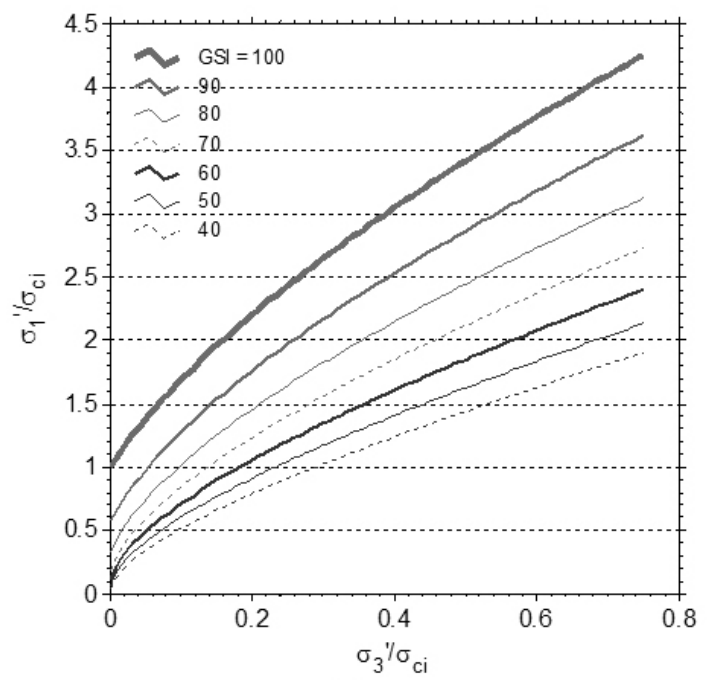

(a)

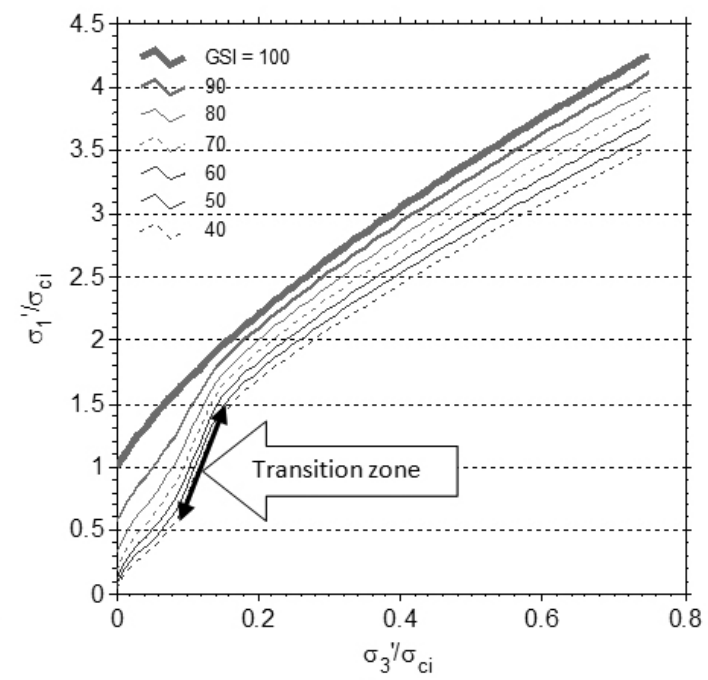

(b)

Figure 1 a) Hoek-Brown empirical failure criteria for rock masses with varying GSI as defined by Equations (1) to (4); b) Modified s-shaped criteria with reduced rock mass strength degradation at high confinement $(M=80$; see below)

Research in the 1990s tackled the issues of brittle rock failure at low confinement (Castro, 1996; Martin et al. 1999; Kaiser et al., 2000; Diederichs, 2003) and showed that for massive to moderately jointed rock masses failing at low confinement, the rock mass strength is not properly estimated by linear, e.g. Mohr-Coulomb, or continuously convex failure envelops (e.g. Hoek-Brown; Equations (1) to (4)) because the processes driving failure at high and low confinement differ.

- At low confinement, tensile crack initiation and propagation is the dominating failure process.

Heterogeneities in the rock mass favour tensile conditions even in an overall compressive setting and thus promote the unstable propagation of tensile cracks leading to spalling (Figure 2a).

- At higher confinement, the unstable propagation of tensile cracks is inhibited and thus shear bands (with an internal tensile fracture structure) will form, leading eventually to failure (Figure 2b).

a)

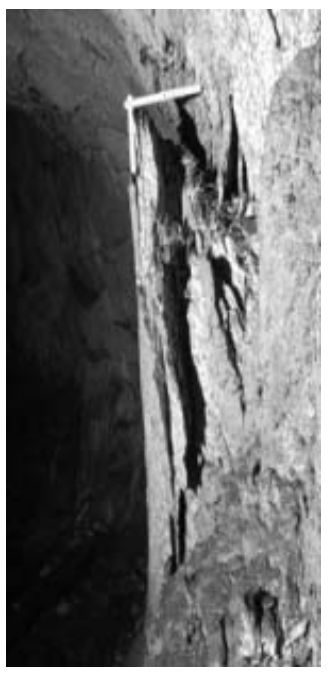

b)

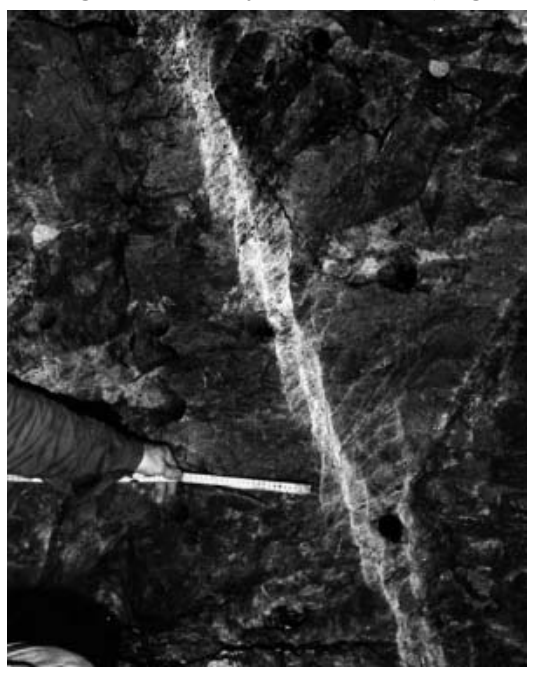

Figure 2 a) Spalling of tunnel wall in brittle failing rock (tensile cracks can grow); b) shear trough intact rock mass, i.e. Ortlepp shear; tensile crack growth is inhibited and constrained to the shear zone (van Aswegen, 2008)

This change in failure mechanism must be reflected by the failure envelope for brittle rocks. In order to account for the unstable tensile crack propagation process at low confinement, a bilinear cutoff was 
introduced (Figure 2.18 in Kaiser et al., 2000). Empirical calibration of this criteria on observation of near excavation failure (spalling leading to $\mathrm{V}$-shaped notches in circular excavations) suggests that the low confinement linear section is obtained by introducing the brittle failure parameters $m_{b}^{b r i t t l e} \sim 0$ and $s^{\text {brittle }}=0.11$ to 0.25 in Equation (1). The linear transition section of the criteria (Figure $1 \mathrm{~b}$ ), known as the spalling limit, was found to be defined by a constant $\sigma_{1} / \sigma_{3}$ ratio ranging from 5 to 20 depending on rock and rock mass heterogeneity and other factors. The behaviour in the higher confinement zone was not investigated in detail and it was assumed that the common criteria defined by Equations (1) to (4) would apply.

The strength depletion at low confinement implied by the brittle failure envelop also reflects another fundamental difference with common failure criteria like the Mohr-Coulomb criteria: the later assumes that both cohesion and frictional strength are mobilised instantaneously and simultaneously and both contribute to the peak strength. However, for rocks under low confinement, dilation inhibits coincidental mobilisation of friction and cohesion as supported by the experimental results of Martin and Chandler (1994) and numerical analyses of Hajiabdolmajid et al. (2000), where the pre-peak behaviour is dominated by cohesion and residual strength by the mobilised frictional strength within the damaged rock.

Unfortunately, there are a very limited number of observations concerning the strength of rock masses under relatively high confinement but, intuitively, one would expect that tensile failure processes are inhibited and that the degradation should be lower at high confinement. Thus, the hypothesis of an s-shaped failure criteria for both intact rock and rock masses was introduced by Kaiser and Kim (2008). It is adopted here and modified to illustrate that the strength of confined rock masses, and thus pillars, may be underestimated using the standard approach presented on Figure 1a.

A modified formulation for the s-shaped failure criterion for the rock mass is proposed here and illustrated by Figure 1b. It is similar to the one presented by Kaiser and Kim (2008) but the degradation factor is related to GSI in a different manner. At low confinement $\left(\sigma_{3}<\sigma_{\mathrm{c} i} / 10\right)$, the failure envelop is identical to the conventional Hoek-Brown criteria with GSI-based degradation $\left(C_{s}=9\right.$ and $\left.C_{m}=28\right)$. However, under high confinement $\left(\sigma_{3}>\sigma_{c i} / 10\right)$, the rock mass strength is less degraded (thus $C_{s}>9$ and $\left.C_{m}>28\right)$. A transition (Figure 1.b) from low confinement to high confinement is built using a sigmoidal function. The details of this transition are yet unclear and the current formulation is constrained at a fixed confinement level of $\sigma_{3}=\sigma_{c i} / 10$. Other aspects of this transition, particularly its abruptness could vary, but in absence of supporting data to constrain the transition slope an abrupt change is currently adopted. The failure criteria presented on Figure $1 \mathrm{~b}$ are obtained using the following equation:

$$
G S I^{\prime}=f\left(\sigma_{3}^{\prime}, G S I, U C S\right)=\frac{M-\frac{M}{100} G S I}{1+e^{-\sigma_{3}^{\prime}+U C S / 10}}+G S I
$$

$G S I^{\prime}$ is a confinement dependent value to replace GSI in Equations (2) to (4) to produce confinement dependent values of $s, m_{b}$ and $a$. With these confinement-dependent parameters in the general Hoek-Brown failure criteria (Equation (1)) the s-shaped criteria presented in Figure $1 \mathrm{~b}$ are obtained. The constant $M$ introduced in Equation (5) controls the degradation at elevated confinement $\left(\sigma_{3}>\sigma_{c i} / 10\right)$. A value of $M=80$ was used to generate the curves presented in Figure 1.b.

At present, it is difficult to estimate values for $M$ and further research by back-analyses of confined failures is required. Nevertheless, there are several reasons for the assumed higher strength at elevated confinement. The main reasons for the higher strength of rock mass under confinement is that rough and wavy joints cannot slip unless some breaks through intact rock occur in order to create the needed degree of freedom for shear movement (Patton, 1966). For this reason, as not all joint surfaces can effectively be mobilised, the effective block size under confinement will be reduced compared to the unconfined conditions (outcrop or excavation walls) under which GSI is usually determined. This suggests that under confinement, the rock mass will behave like a massive to moderately jointed rock mass and GSI will be capped at a value of about 80 (a value $M=80$ caps GSI at 80 for high confinements). Of course this is clearly not the case when the intact rock strength is low or the joints are very weak, e.g. clay filled.

The data presented in Figure 3a are from uniaxial and triaxial tests on standard-sized quartzite samples (50 $\mathrm{mm}$ diameter). These samples include various levels of heterogeneities and are used here as an analogue for a rock mass to investigate the strength degradation ratio at low and high confinement levels. At low 
confinement, a reasonable fit to the data range is achieved using GSI values from 100 (intact rock) to 50 (jointed) and the standard degradation factors $C_{s}$ and $C_{\mathrm{m}}$. At higher confinement, using standard HoekBrown criteria with GSI varying from 100 to 50, an excessive strength reduction is generated which is not reflected in the diminution of the data scatter toward higher strength with increasing confinement. The use of the modified approach to obtain the s-shaped failure criteria with $M=80$ appears to reflect the data range well (even though we recognise the rather limited data number). A similar fitting result is presented on Figure $3 \mathrm{~b}$ for a marble showing two different textures, an intact and a granulated marble. The granulated marble can again be considered as an analogue for a rock mass, i.e. the granulation in the specimen would represent a degradation that causes a reduction in strength from intact to the rock mass.

Further work is required to determine with confidence the appropriate value for $M$ and to refine the detailed shape in the transition area. For the remainder of the paper, $M=80$ and an abrupt transition at $\sigma_{3}<\sigma_{c i} / 10$ is assumed.

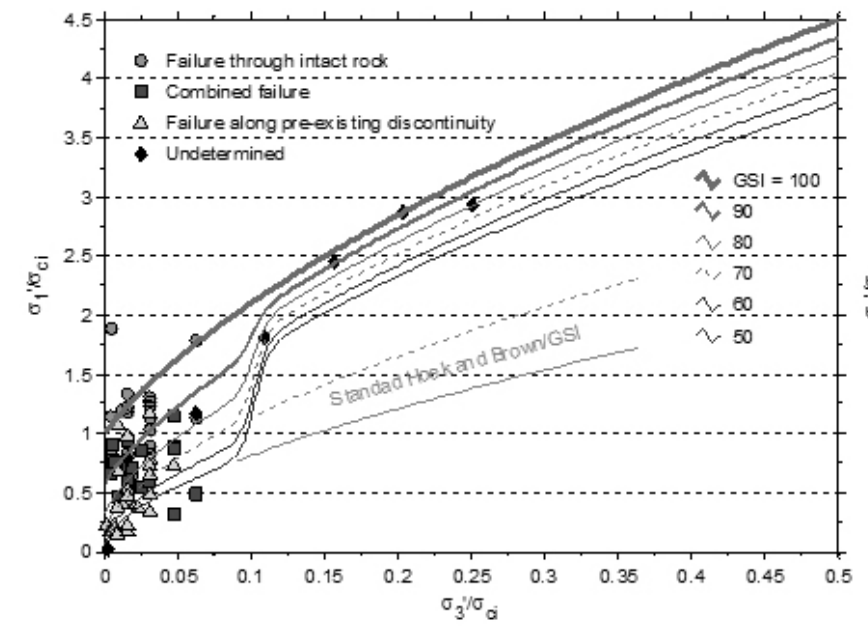

a)

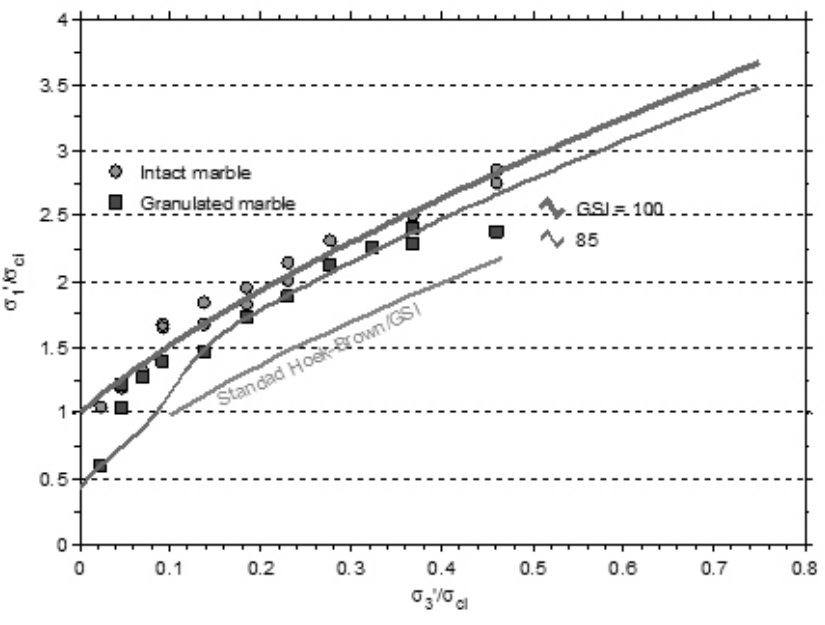

b)

Figure 3 Fit of the modified failure criteria: a) Quartzite laboratory compressive test data; b) Marble laboratory compressive test data (poor fit in the transition section indicates that the transition for the marble occurs at a lower spalling limit, at about $\sigma_{3}=\sigma_{\mathrm{c} i} / 20$ )

\section{Commonly adopted pillar strength estimation methodologies}

The current practice of pillar design commonly involves:

- Empirical formulae that are based on best-fit equations related to observed pillar performance data (Lunder, 1994)

- Use of numerical stress modelling tools such as:

- Continuum numerical stress modelling and various rock mass strength criterion (Maybee, 2000; Esterhuizen, 2006)

- Displacement discontinuity methods (Roberts et al., 1998; 2007)

- Use of discrete numerical stress modelling codes to attempt to simulate the progressive failure of pillars (Elmo et al., 2010).

While a number of cases are available for the empirical evaluation of pillar stability (Figure 4a), the dataset is limited and the majority of the cases are from shallow depths $(<600 \mathrm{~m}$; no cases deeper than $1,000 \mathrm{~m}$; there are only two failed pillar cases above a $\mathrm{W} / \mathrm{H}$ of 1.5 and no failed cases after $\mathrm{W} / \mathrm{H}$ of $\sim 2.3$ ); various pillar types are included in the dataset that that would not likely display the same behaviour, e.g. open stope rib pillars (Hudyma, 1988) compared to square pillars or rib pillars (Lunder, 1994), and the dataset contains cases from various stress regimes, i.e. $K_{o}$ ranging from 0.5 to $>2$. Because of these limitations, empirical criteria based on this dataset are not appropriate for pillar sizing at depths $>1,000 \mathrm{~m}$ and for width to height 
W/H-ratios greater than about 1.5 to 2. It is most striking that the data fits by Lunder and Pakalnis (1997) and Hedley and Grant (1972) suggest a horizontal asymptote, while the curves produced by Martin and Maybee (2000) using brittle Hoek-Brown parameters, and as recently shown by Mortazavi et al. (2009), converge toward a vertical asymptote. Intuitively, an asymptotic relationship with a finite strength for wide pillars or a linearly increasing strength with pillar width, do not make sense because a horizontal asymptote would suggest that very wide pillars would have a finite strength.

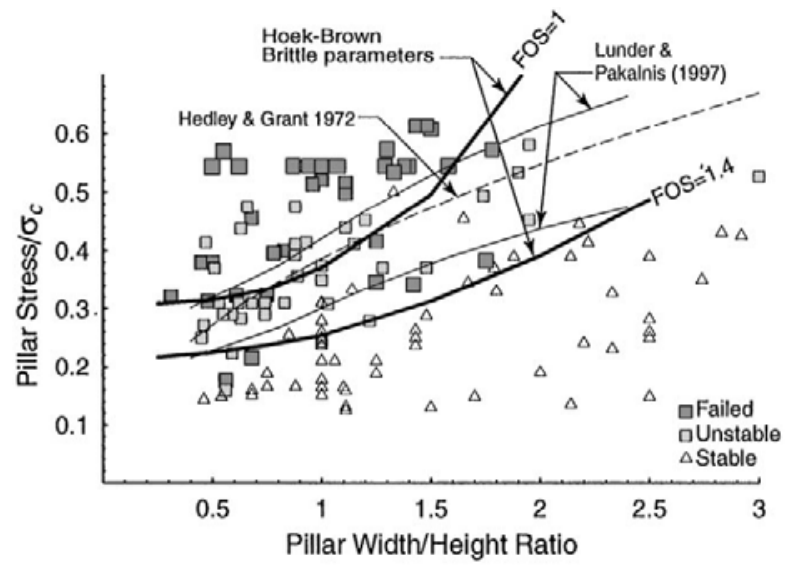

a)

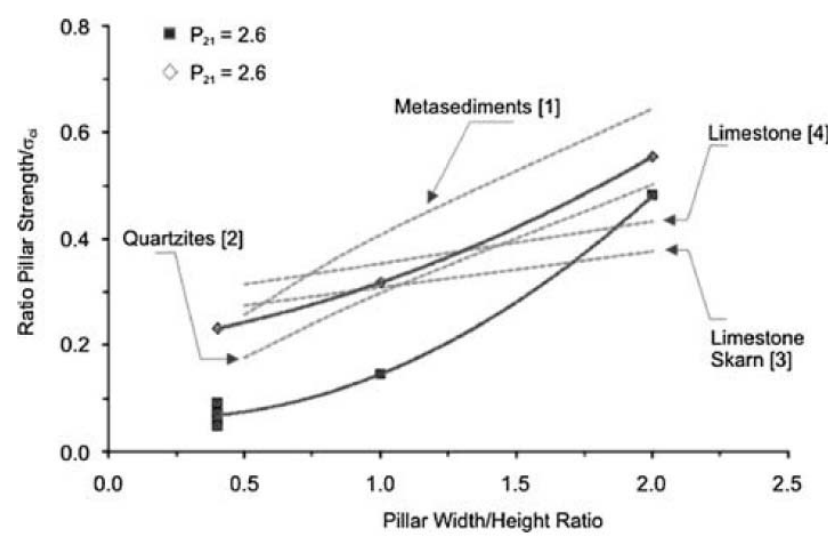

b)

Figure 4 a) Pillar stability graph with Phase $^{2}$ modelling results using the Hoek-Brown brittle parameters (Maybee and Martin, 2000; Maybee, 2000); b) Comparison of results from simulations by Elmo et al. (2010) with empirical trends: [1] Von Kimmelmann et al. (1984), [2] Hedley and Grant (1972), [3] Sjoberg (1992) and [4] Krauland and Soder (1987)

Considering a limiting strength of normalised pillar stress $p_{s} / \sigma_{c}=0.65$ (Figure 4), pillars could not be stable at depth as illustrated by Figure 5 . For example, for a $U C S=100 \mathrm{MPa}$, pillars would become unstable at $1800 \mathrm{~m}$ when the extraction ratio $(E R)$ is equal to $25 \%$ and at $1200 \mathrm{~m}$ for $E R=50 \%$. This is clearly not the case as discussed in this paper based on South African experience.

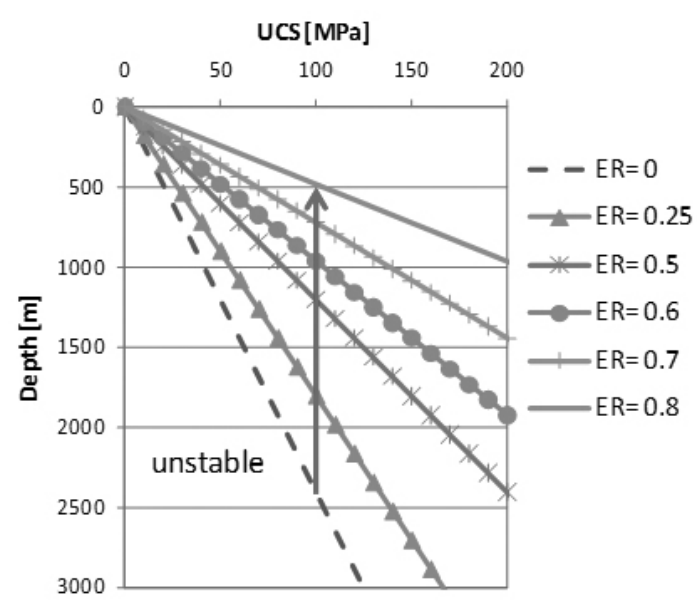

Figure 5 Limiting depth for stable pillars as a function of UCS and extraction ratio, ER, for an assumed $p_{s} / U C S=0.65$ as per Figure $4 a$ using tributary area stress analysis and a vertical stress gradient of $0.027 \mathrm{MPa} / \mathrm{m}$

Based on distinctly different modelling methodologies, both taking into account brittle failure mechanisms, Elmo et al. (2010) and Martin and Maybee (2000) showed that the pillar stability curves should be upward curved with significant strength increases at $\mathrm{W} / \mathrm{H}$ ratios $>1.5$ to 2 (Figures $4 \mathrm{a}, 4 \mathrm{~b}$, and 6 ). 


\subsection{Confinement and pillar strength}

Common pillar strength relationships after Salamon (1967), Salamon and Oravecz (1976), Hedley and Grant (1972), and Lunder and Pakalnis (1997) indicate decreasing rate of strength increase for increasing pillar width to height $\mathrm{W} / \mathrm{H}-$ ratios (Figure 4). A strengthening effect due to confinement has been recognised in South African mines as it is conventionally accepted that once a pillar reaches a W/H-ratio of 10:1 it is considered to be 'indestructible' (Wagner and Madden, 1984). The strength relationship for pillars proposed by Stacey and Page (1986), based on the results of the laboratory tests of Wagner and Madden (1984) who assessed the strengthening effect due to confinement, is presented in Figure 6a. It shows increasing pillar strength if W/H-ratio exceeds about 4.5. This is contrary to the evidence discussed above (Hedley and Grant, 1972; Lunder, 1994). It is also contrary to evidence presented below which suggests that pillar strength should increase more rapidly with increasing $\mathrm{W} / \mathrm{H}$ due to reduced degradation of the pillar core as a result of confining pressure. Even without changes in degradation, recent numerical stress modelling work, e.g. by Mortazavi et al. (2009); using Mohr-Coulomb criterion, Maybee (2000; $K_{o}=1.5$; the dashed and dotted lines indicated anticipated trends beyond cases modelled) and Elmo et al. (2010) (as previously noted and shown in Figure 6b) suggests that this strength increase should occur around a W/H-ratio of 1.5 to 2 . This is consistent with the previous quoted database that did not show any failed cases for $\mathrm{W} / \mathrm{H}>2.3$.

It would therefore be anticipated that pillar stability curves should tend to infinity at $\mathrm{W} / \mathrm{H}>\sim 2$. This trend may however be capped by a bearing capacity type failure of the roof or floor rock. The limiting stress for pillar punch failure has been estimated using standard bearing capacity formulations and GSI-based strength estimates (Stacey and Page, 1986). Two bearing capacity limits are shown in Figure $6 \mathrm{~b}$ together with various pillar stability graphs. This indicates that strong pillars on relatively weak foundations, e.g. $\mathrm{GSI}_{\text {foundation }}=40<\mathrm{GSI}_{\text {pillar }}$, will not be able to carry loads in excess of those predicted by the pillar stability graphs. However, for pillars on a strong foundation, e.g. GSI $>40$, the question of elevated pillar strength due to a reduced rock mass degradation in the core is of interest.

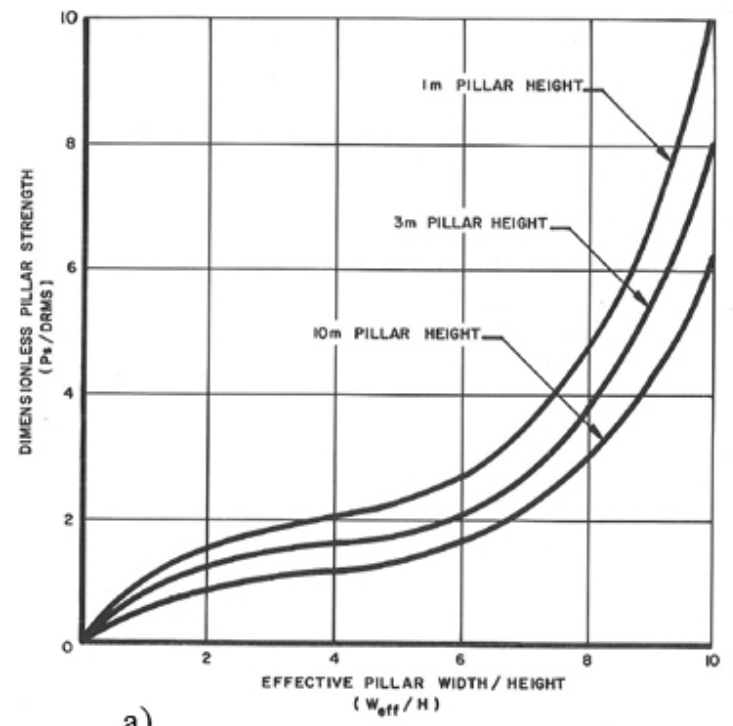

a)

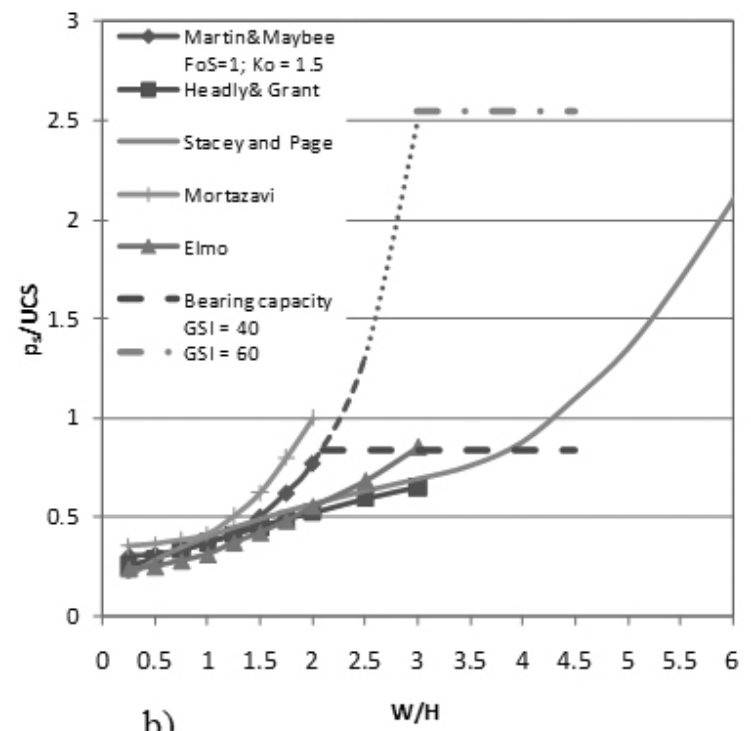

b)

Figure 6 a) Pillar strength with changing width to height ratio (after Stacey and Page, 1986); b) re-plotted pillar strength graphs on expanded scale (various authors) with bearing capacity estimates for pillar foundation failure (roof or floor) at GSI $=\mathbf{4 0}$ and 60

In summary, current empirical pillar stability approaches seem to be limited to pillars with $\mathrm{W} / \mathrm{H}$ ratios $<1.5$ to 2 and for shallow depths $(<600 \mathrm{~m})$, and therefore do not apply for the design of pillars at depths $>1000 \mathrm{~m}$. There is evidence, predominantly from South African mining as well as from numerical stress modelling studies that pillar strength potentially increases between a W/H-ratio of 1.5 and 5 and tends to a strength controlled by foundation failure as W/H-ratio approaches 3 to 10:1. 


\section{$4 \quad$ Pillar strength base on modified s-shape rock mass failure criterion}

\subsection{Pillar capacity comparison using elastic approach}

A comparison of the strength of pillars using the general Hoek-Brown and the modified s-shaped failure criterion is presented next. First, the pillar capacity is evaluated using an elastic model. The stresses in the pillars are computed using the plane-strain stress analysis software Examine2D (Rocscience, 2010) based on the Boundary Element Method. An example of stresses in pillars with two W/H-ratios is presented in Figures $7 \mathrm{a}$ to $7 \mathrm{~d}$ (minor and major principal stresses). The stress distribution in the pillar for these two cases, stress at each node, is plotted in Figure $7 \mathrm{e}$ and $\mathrm{f}$ in the principal stress space.

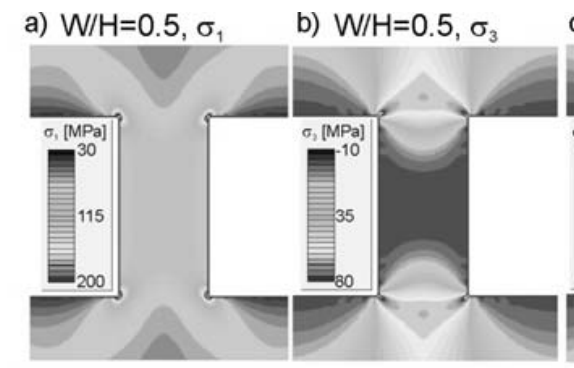

e)

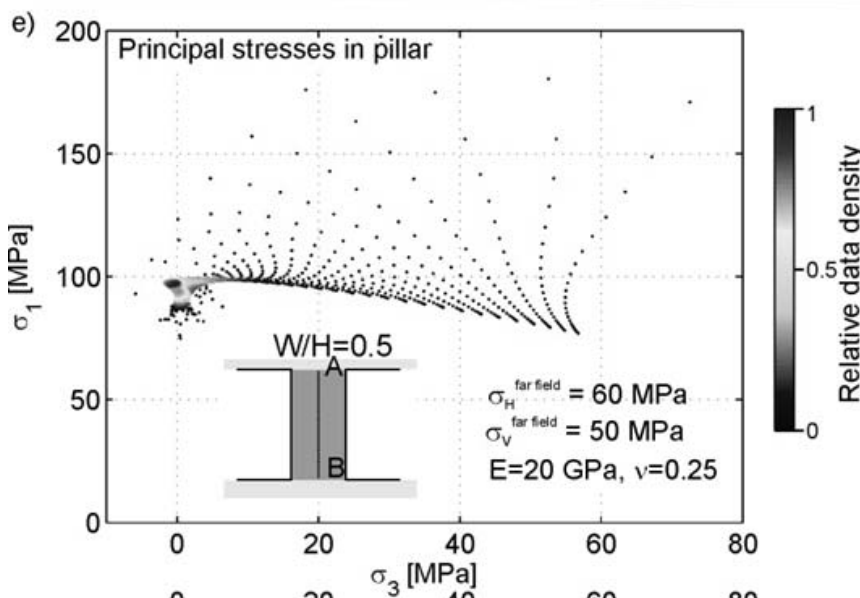

c) $\mathrm{W} / \mathrm{H}=2.0, \sigma_{3}$
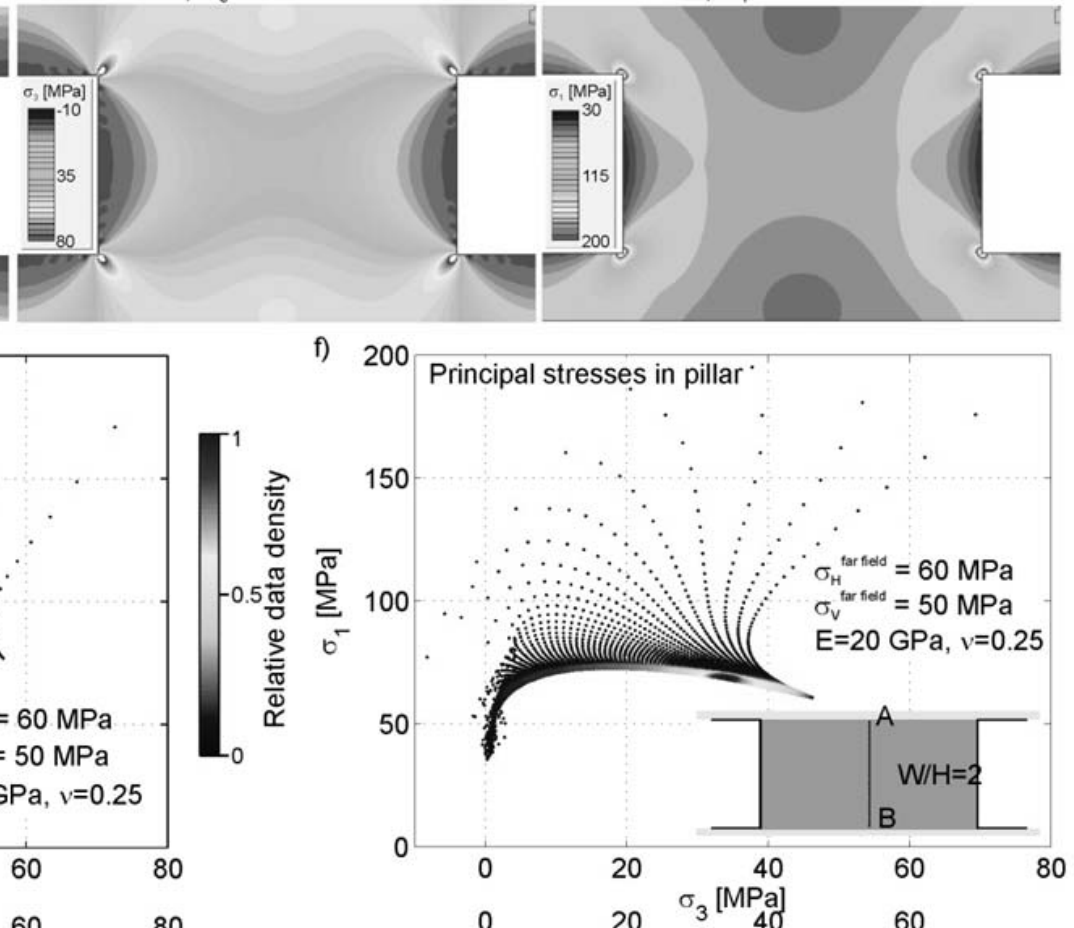

h)

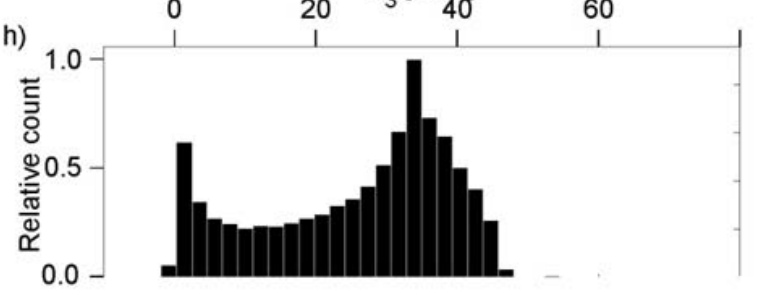

Figure 7 Stress state in pillars, for far field stresses assumption of $\sigma_{\mathrm{H}}=60 \mathrm{MPa}$ and $\sigma_{\mathrm{V}}=50 \mathrm{MPa}$, with $\mathrm{W} / \mathrm{H}$ ratio of 0.5 and 2.0 : a) major principal stress $\left(\sigma_{1}\right)$ contour in a $\mathrm{W} / \mathrm{H}=0.5$ pillar; b) minor principal stress $\left(\sigma_{3}\right)$ contours in a $W / H=0.5$ pillar; c) $\sigma_{3}$ and d) $\sigma_{1}$ contours in $\mathrm{W} / \mathrm{H}=\mathbf{2 . 0}$ pillar; e) and $\mathrm{f}$ ) show respective principal stresses at nodes along a regular grid pattern covering the pillar (darker grey area in inserts of pillar sketches, grid spacing: 100 nodes along pillar height) in pillars with $\mathrm{W} / \mathrm{H}=0.5$ and 2 . As many data points overlap, points are shaded by relative data density in order to highlights where a lot of points are located. This is also highlighted by the histograms of $\sigma_{3}$ presented in $\mathrm{g}$ ) for a $\mathrm{W} / \mathrm{H}=0.5$ and $\mathrm{h}$ ) for a $\mathrm{W} / \mathrm{H}=\mathbf{2 . 0}$ pillar

The stresses are obviously higher in the narrow pillar. A common means of evaluating the overall stress level in a pillar is to calculate the average pillar stress (APS or $\mathrm{p}_{\mathrm{s}}$ ). However, there is some uncertainty in how this stress is computed by various authors. For large arrays of pillars in a room and pillar setting and at sufficient distance from the abutment, APS is usually computed using the tributary area method (Salamon, 1967). For 
isolated pillars, APS is often set equal to the maximum stress at the pillar centre or by averaging stresses over various domains. In this paper, the average pillar stress is estimated by averaging the vertical stress component computed from an elastic simulation along a line centred in the pillar (line A-B on Figure 7e and 7f). This provides a best fit to the tributary area approach when a large number of pillars are included. It is also in agreement with equations in Ozbay and Ryder (1989) (referring to Salamon's (1967) work). For the two cases presented on Figure 7; APS equal to $95 \mathrm{MPa}(\mathrm{W} / \mathrm{H}=0.5)$ and $66 \mathrm{MPa}(\mathrm{W} / \mathrm{H}=2)$.

The confinement distribution differs significantly for the two cases. As many data points overlap in Figure 7e and $7 \mathrm{f}$, points are shaded by relative data density in order to highlight where a lot of points are located. This is also highlighted by the histograms of $\sigma_{3}$ presented in Figure $7 \mathrm{~g}$ for a $\mathrm{W} / \mathrm{H}=0.5$ and Figure $7 \mathrm{~h}$ for a $\mathrm{W} / \mathrm{H}=2.0$ pillar. For the narrow pillar, most of the pillar is under low (about zero) confinement as shown by the relative density plot in Figure 7e and histogram of Figure $7 \mathrm{~g}$. In the wider case, the majority of the pillar is highly confined at about $35 \mathrm{MPa}$ as shown by Figure $7 \mathrm{~h}$.

a)

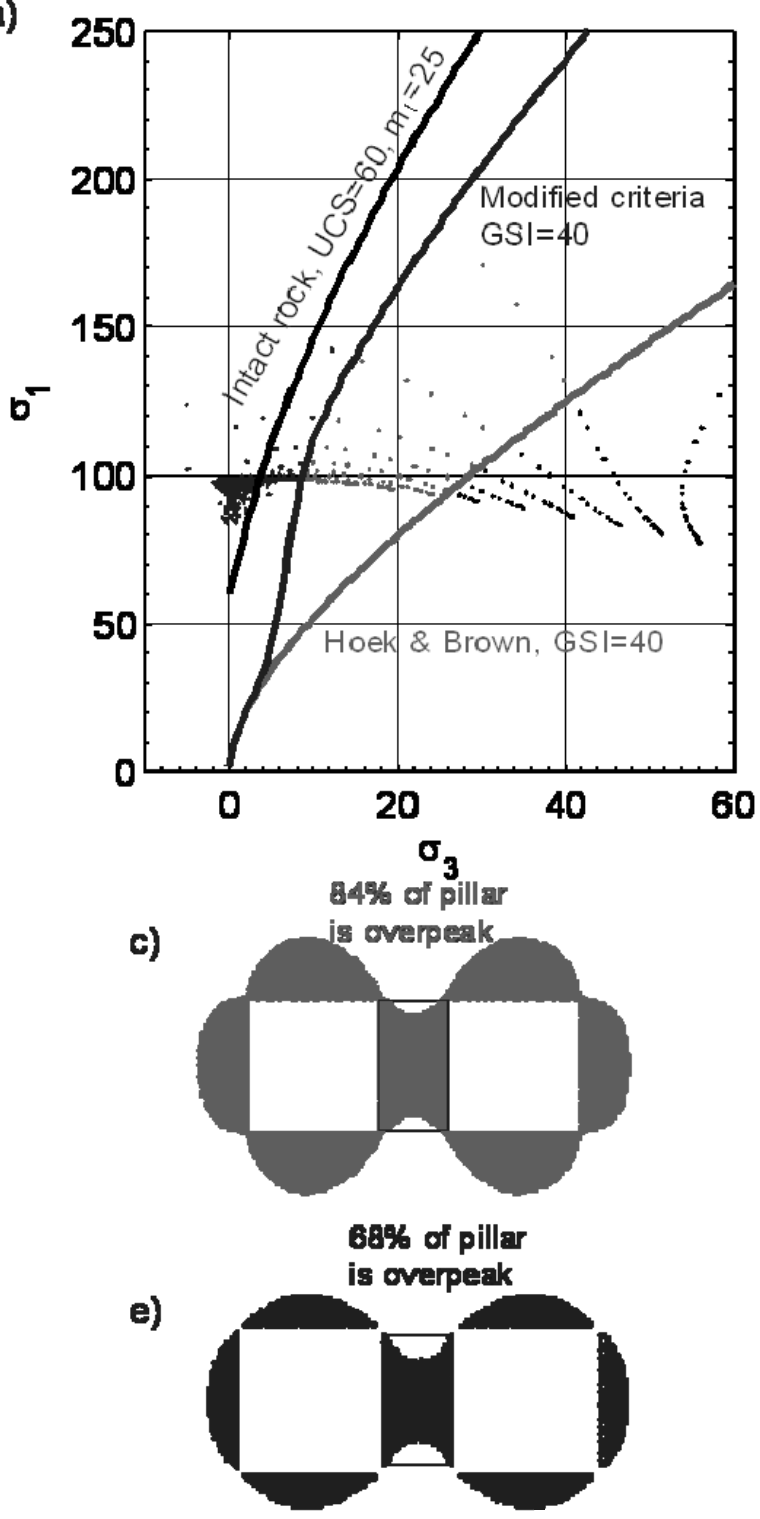

b)

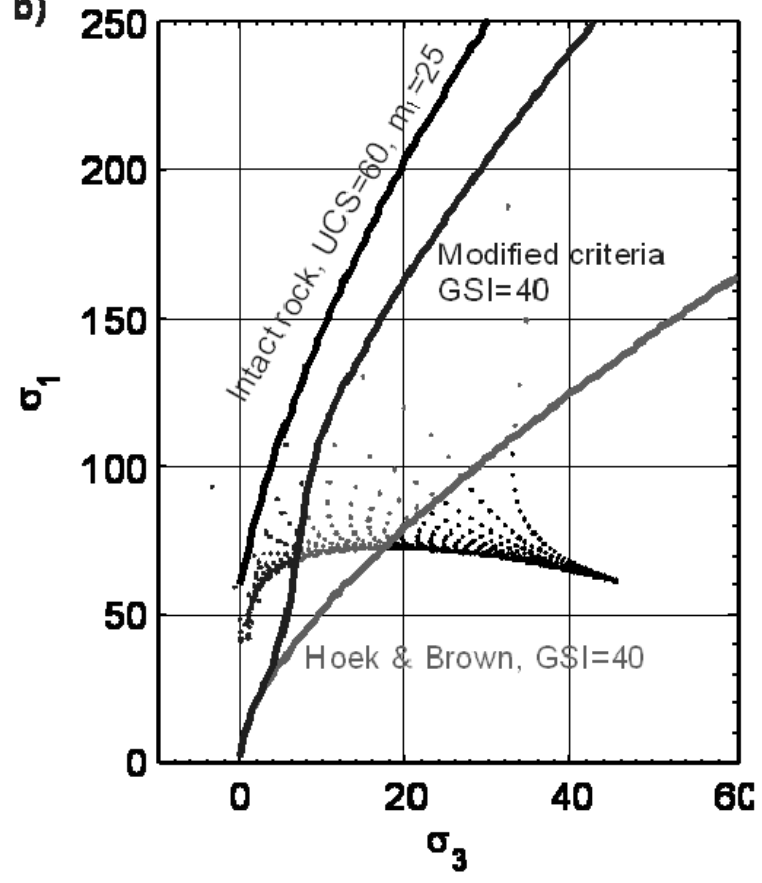

d)

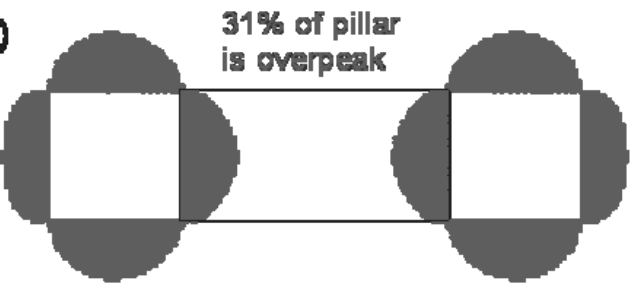

f)

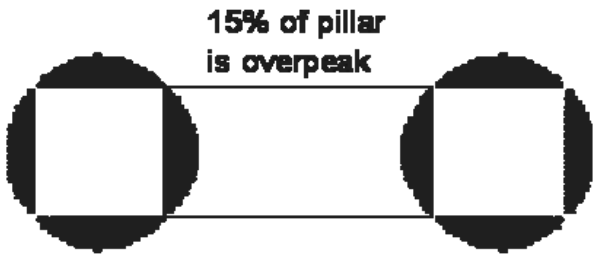

Figure 8 a) and b) stress in pillars with two different width to high ratios (same cases as in Figure 7) including failure criteria; c) and d) nodes with stress state exceeding the Hoek-Brown failure criteria; e) and f) same for the modified, s-shaped failure criteria

Figure 8 compares the state of stress presented in Figure 7 with the general Hoek-Brown and modified, s-shaped failure criteria. The intact rock strength is specified on the figure and the rock mass strength 
degradation is computed considering a GSI of 40. A larger area of the narrow pillar is over the peak strength for the general Hoek-Brown than for the modified case, particularly in the case of the wide pillar where, as seen in Figure 7, the majority of the pillar is under high confinement.

A generalisation of this approach for pillar $\mathrm{W} / \mathrm{H}$ ratio from 0.2 to 3 is presented in Figure 9. It can be seen that the results between the two failure criteria are significantly different, particularly in the W/H range of 1.0 to 1.8. Also, if one considers the percentage of area over peak being a proxy for pillar stability, it can be seen that a pillar with a W/H-ratio of 1.0 considering the modified, s-shaped failure criteria will be in the same relative stability state as a pillar with a W/H-ratio of 1.7 considering the general Hoek-Brown failure criteria.

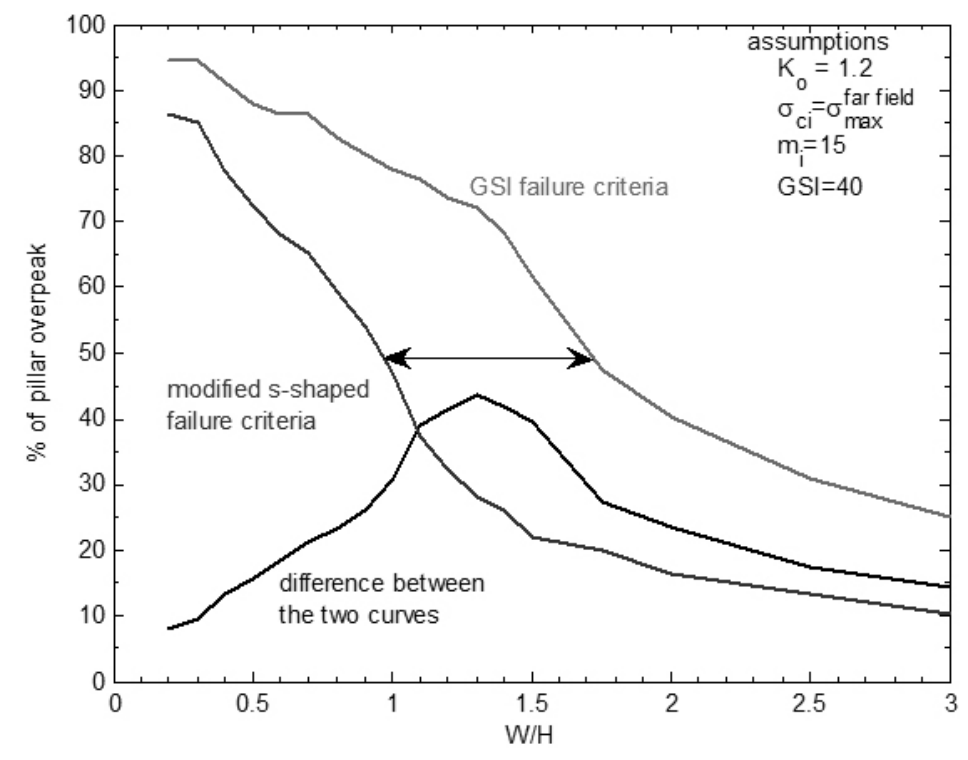
Figure 9 Comparison of the percentage of area of pillar over-peak for two failure criteria (general
Hoek-Brown and modified s-shape criteria)

In other words, if the validity of the modified s-shaped failure criteria can be demonstrated, there is much potential for improving the optimisation of pillar design.

\subsection{Pillar behaviour comparison using plastic approach}

Next, a comparison of the strength of pillars using the general Hoek-Brown and the modified s-shaped failure criterion is presented using an elastic-brittle-plastic model.

Similar to contours of constant minor principal stresses, the contours of equal rock strength are essentially parallel to the $\sigma_{3}$-contours (Kaiser and Kim, 2008), and thus the rock strength distribution in the radial direction around an excavation is almost independent of $\mathrm{K}_{\mathrm{o}}$ (except in extreme cases). Most importantly, the rock strength is relatively low near the excavation, due to low confinement, and then rapidly increases to about double strength at a distance from the wall of about $50 \%$ of the tunnel radius.

Based on the previous discussion, it is assumed that a weaker inner shell is limited to the $\sigma_{3}$-contour at $10 \%$ of the UCS of intact rock. Outside this contour, in the outer-shell, the rock mass is stronger as defined by the modified, s-shaped criteria. In this manner, the effect of confinement on pillar strength can be investigated. The effect of confinement is simulated by assigning respective material properties for the inner and outer shell. Phase2 (Rocscience, 2010), a commercial finite element software program, was chosen for this study and Table 1 presents the mechanical properties used as input parameters for the outer shell. For the inner shell, it was assumed that the residual strength for the general Hoek-Brown criteria is $25 \%$ of the peak strength. For the modified strength approach, at GSI $=60$, the residual strength was set to 25 and $50 \%$ of peak in inner and outer shells, respectively. 
Table 1 Mechanical properties for the analysis

\begin{tabular}{cccccccc}
\hline $\begin{array}{c}\text { UCS } \\
(\mathbf{M P a})\end{array}$ & $\begin{array}{c}\text { Elastic Modulus } \\
\mathbf{( M P a )}\end{array}$ & $\begin{array}{c}\text { Poisson's } \\
\text { Ratio }\end{array}$ & $\mathbf{m}_{\mathbf{1}}$ & GSI & $\begin{array}{c}\boldsymbol{\sigma}_{\mathbf{v}} \\
(\mathbf{M P a})\end{array}$ & $\begin{array}{c}\boldsymbol{\sigma}_{\mathbf{H}} \\
(\mathbf{M P a}\end{array}$ & $\begin{array}{c}\boldsymbol{\sigma}_{\mathbf{h}} \\
(\mathbf{M P a})\end{array}$ \\
\hline 250 & 20,000 & 0.25 & 25 & 60 & 25 & 30 & 27.5 \\
\hline
\end{tabular}

Five different ratios of width to height were analysed: $\mathrm{W} / \mathrm{H}=0.5,1.0,1.5,2.0$ and 2.5. The $\sigma_{3}$-contours corresponding to $10 \%$ of UCS contour were determined from an elastic model and then used to assign inner and outer shell properties. Figure 10 indicates the $\sigma_{3}$-contours of $25 \mathrm{MPa}$ which corresponds to $10 \%$ of an UCS of $250 \mathrm{MPa}$ in the case of $\mathrm{W} / \mathrm{H}=1.5$. These contours were exported to the plastic models and used as material boundaries.

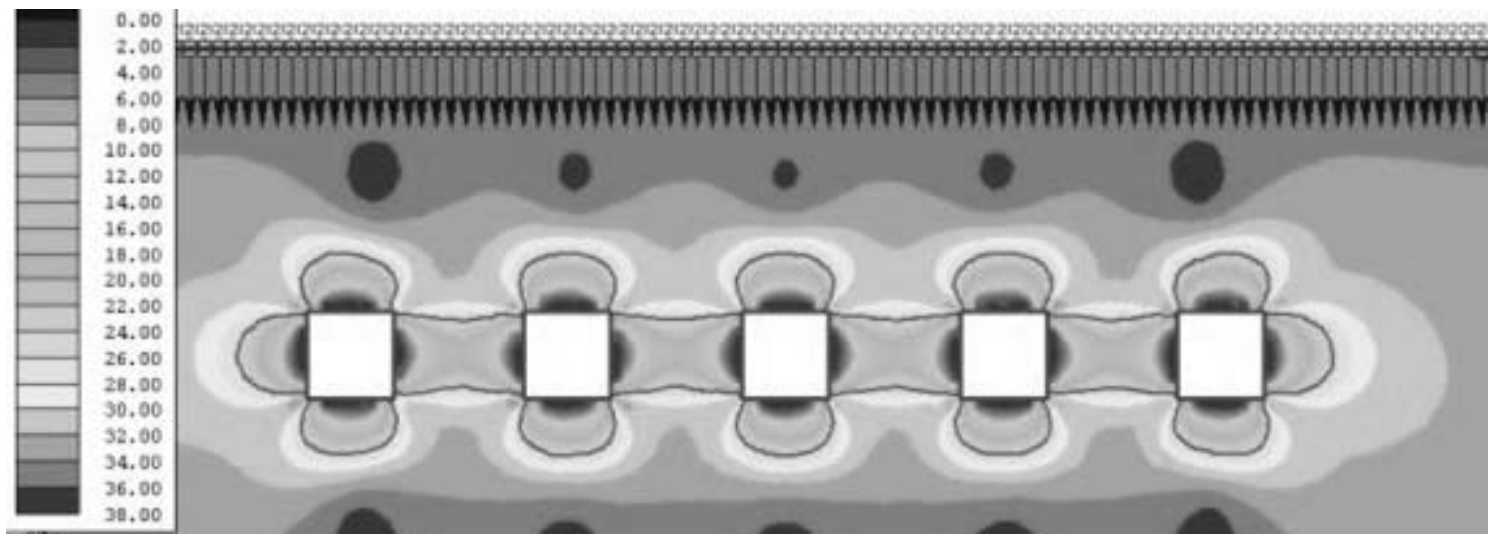

Figure $10 \sigma_{3}$-contours for $\mathrm{W} / \mathrm{H}$ ratio $=1.5$ with inner/outer shell boundary at $25 \mathrm{MPa}$ highlighted for case with $\mathrm{W} / \mathrm{H}=1.5$

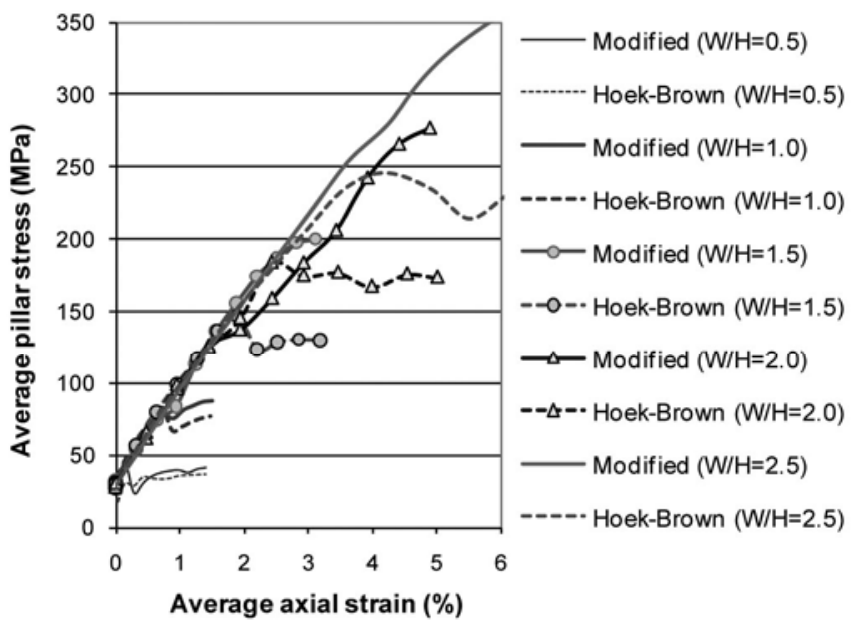

a)

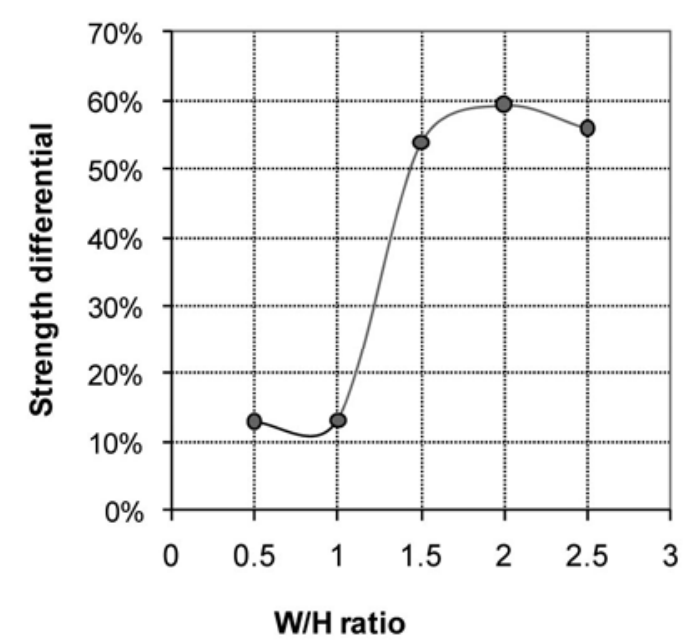

b)

Figure 11 Numerical tests with general Hoek-Brown and modified, s-shaped failure criteria for various W/H ratios: a) pillar stress versus strain; and b) pillar strength differential between $\mathrm{H}-\mathrm{B}$ and modified strength criteria at final loading step

The model was incrementally loaded by vertical straining and the resulting stress and strain curves are plotted in Figure 11a. The stress is the average major principal stress calculated along a horizontal line within the pillars and the strain is the average vertical strain in the pillar (ratio of vertical displacement to the original pillar height). 
For pillars wider than $\mathrm{W} / \mathrm{H}=1$, the pillars with the modified, s-shaped criteria have not yet reached peak strength compared to the pillars modelled with the general Hoek-Brown criterion when they have reached peak strength. As a consequence, the strength differential between the two cases increases as the pillars are strained and the differential at the maximum modelled strain is plotted in Figure 11b. At the arbitrarily selected maximum strains between 3 and $6 \%$, when the model loading was terminated, the strength differential exceeds $50 \%$ for $\mathrm{W} / \mathrm{H}=1.5$ to 2.5 . The differential is only about $11 \%$ for the narrow pillars $(\mathrm{W} / \mathrm{H}=0.5$ to 1$)$.

This illustrates that pillars may have significant strength reserves when strained beyond failure initiation according to the general Hoek-Brown criteria. From a practical perspective, it must be noted that this strength reserve is only mobilised at large strains. Thus, yielding wall control measures will be required to capitalise on the strength reserve in the core. This may also explain why there are data points labelled as 'failed' in Figure 4a. When pillar width exceeds $1.5 \mathrm{H}$, the pillar core can provide significant resistance but the strain is high leading to wall deteriorations that could be similar as observed in failed pillars.

The findings presented here are consistent with experiences with the use of crush pillars in South African mines where pillars are formed in stress-fractured rock ahead of the mining face (Ryder and Ozbay, 1990; Ozbay et al., 1995; York and Canbulat, 1998). For W/H $<\sim 1.5$, the inner shell behaviour tends to dominate the pillar behaviour and steady yielding pillars with a more or less constant post-peak strength can be achieved.

\section{Conclusions}

Construction of infrastructure in deep underground mines depends heavily on both an understanding of near wall rock behaviour as well as the ultimate load bearing capacity of confined rock, and thus on a reliable strength criterion for the rock near and far from the excavations. Kaiser and Kim (2008) suggested that the failure envelop for the entire confinement range of brittle rocks and rock masses should be s-shaped when highly confined, such as when designing pillars at depth. If validated, this impacts engineering problems such as pillar design where both wall instability and confined rock mass stability issues need to be considered.

The limitations and potential opportunities in pillar design resulting from the impact of an s-shaped failure criteria were explored by numerical studies using both conventional and the modified s-shaped failure criteria with reduced degradation at high confinement (beyond the spalling limit). It is illustrated that current empirical design rules are flawed and tend to be conservative, potentially leading to uneconomic pillar designs at depth and in brittle failing rock. When confined in the core of pillars, the rock mass may exhibit superior strength as it does no longer fail by spalling propagation from the walls.

It is shown that the strengths of pillars with width to height ratios $(\mathrm{W} / \mathrm{H})$ exceeding 1.5 to 2 may be systematically underestimated, as the core retains strength reserves that can be mobilised with increasing strain. As a consequence, pillar designs based on current empirical rules may be inadvertently conservative and thus not optimal from an economic perspective. This aspect is of particular interest for block caves where drawpoint spacing may have a significant impact on cave propagation, recovery performance, and economics.

It is recommended that field observations be used to verify the validity of the hypothesis presented here. The results of the analyses presented in this paper suggest that pillars at depth may be substantially stronger than anticipated by conventional failure criteria and by empirical criteria.

\section{Acknowledgements}

This research is supported by CEMI's industrial sponsors, the Government of Ontario through its Ministry of Research and Innovation and by Natural Sciences and Engineering Research Council of Canada (NSERC). 


\section{References}

Castro, L.A.M. (1996) Analysis of Stress Induced Damage Initiation around Deep Openings Excavated in a Moderately Jointed Brittle Rock Mass. Ph.D. Thesis, Dep. of Civil and Rock Mechanics Eng., University of Toronto, 455 p.

Diederichs, M.S. (2003) Manuel Rocha medal recipient rock fracture and collapse under low confinement conditions. Rock Mechanics and Rock Engineering 36(5): pp. 339-381.

Elmo, D. and Stead, D. (2010) An Integrated Numerical Modelling-Discrete Fracture Network Approach Applied to the Characterization of Rock Mass Strength of Naturally Fractured Pillars. Rock Mech. Rock Eng. 43: pp. 3-19.

Esterhuizen, G.S. (2006) Evaluation of the Strength of Slender Pillars. Trans. Soc. Min. Metal. Explor. 320: pp. 69-76.

Hajiabdolmajid, V., Martin, C.D. and Kaiser, P.K. (2000) Modelling brittle failure, in Proceedings 4th North American Rock Mechanics Symposium, Seattle, Washington. A.A. Balkema, Rotterdam, 8 p.

Hedley, D.G.F. and Grant, F. (1972) Stope-and-pillar design for the Elliot Lake Uranium Mines. Bull. Can. Inst. Min. Metall., 65: pp. 37-44.

Hoek, E. and Brown, E.T. (1997) Practical estimates of rock mass strength. International Journal of Rock Mechanics and Mining Sciences 34(8): pp. 1165-1186.

Hoek, E., Carranza-Torres, C. and Corkum, B. (2002) Hoek-brown failure criterion - 2002 edition, In NARMS-TAC Conference, pp. 267-273.

Hudyma, M.R. (1988) Development of Empirical Rib Pillar Design Criterion for Open Stope Mining, M.A.Sc. Thesis, University of British Columbia.

Kaiser, P.K. (2010) How highly stressed brittle rock failure impacts tunnel design. Keynote lecture, EUROCK2010, Switzerland, $12 \mathrm{p}$.

Kaiser, P.K., Diederichs, M.S., Martin, C.D., Sharp, J. and Steiner, W. (2000) Underground works in hard rock tunnelling and mining, in Proceedings Geo-Eng2000. Int. Conf. Geotech. and Geol. Eng., pp. 841-926.

Kaiser, P.K. and Kim, B. (2008) Rock mechanics advances of underground construction and mining. Keynote lecture, Korea Rock Mech. Symposium, South Korea, pp. 1-16.

Krauland, N. and Soder, P.E. (1987) Determining pillar strength from pillar failure observations. Eng. Min. J. 8: pp. 34-40.

Lunder, P.J. (1994) Hard Rock Pillar Strength Estimation an Applied Empirical Approach. M.A.Sc. Thesis, University of British Columbia.

Lunder, P.J. and Pakalnis, R.C. (1997) Determination of the strength of hard-rock mine pillars. Bull. Can. Inst. Min. Metall., 90(1013): pp. 51-55.

Martin, C.D. and Chandler, N.A. (1994) The progressive fracture of lac du bonnet granite. International Journal of Rock Mechanics and Mining Sciences \& Geomechanics Abstracts 31(6): pp. 643-659.

Martin, C.D., Kaiser, P.K. and McCreath, D. (1999) Hoek-brown parameters for predicting the depth of brittle failure around tunnels. Canadian Geotechnical Journal 36: pp. 136-151.

Martin, C. and Maybee, W.G. (2000) The strength of hard-rock pillars. International Journal of Rock Mechanics and Mining Sciences, 37(8): pp. 1239-1246.

Maybee, W.G. (2000) Pillar Design in Hard Brittle Rocks. M.A.Sc. Thesis, Laurentian University.

Mortazavi, A., Hassani, F.P. and Shabani, M. (2009) A numerical investigation of rock pillar failure mechanism in underground openings. Computers and Geotechnics. 36: pp. 691-697.

Ozbay, M.U. and Ryder, J.A. (1989) Investigations into foundation failure mechanism of hard rock squat rib pillars. In Maury and Fourmaintraux (eds), Rock at great depth, pp. 527-535.

Ozbay, M.U., Ryder, J.A. and Jager, A.J. (1995) The design of pillar systems as practised in shallow hard-rock tabular mines in South Africa. Journal S. Afr. Inst. Min. Metall., 95(1): pp. 7-18.

Patton, F.D. (1966) Multiple mode of shear failure in rock, in Proceedings 1st International Conference of Rock Mechanics, Lisbon, pp. 509-513.

Roberts, D.P., Tolfree, D. and McIntire, (2007) Using Confinement as a Means to Estimate Pillar Strength in a Room and Pillar Mine, in Proceedings 1st Canada-US Rock Mechanics Symposium, Vancouver Canada.

Roberts, D.P., Lane, W.L. and Yanske, T.R. (1998) Pillar Extraction at the Doe Run Company, AusIMM'98 - The Mining Cycle, pp. 227-234.

Rocscience (2010) Examine2D, a 2-dimensional plane strain indirect boundary element program for the elastic stress analysis, Rocscience, Toronto, Canada.

Rocsience (2010) Phase2, ver. 7.0, Finite element analysis for excavation, Rocscience, Toronto, Canada.

Ryder, J.A. and Ozbay, M.U. (1990) A methodology for designing pillar layouts for shallow mines, ISRM Symp. 'Static and Dynamic Considerations in Rock Engineering, Swaziland, pp. 273-286.

Salamon, M.D.G. and Oravecz, K.I. (1976) Rock Mechanics in Coal Mining, Chamber of Mines of South Africa.

Salamon, M.D.G. (1967) A method of designing bord and pillar workings, Journal of the South African Institute of Mining and Metallurgy, pp. 68-72.

Sjoberg, J. (1992) Failure modes and pillar behaviour in the Zinkgruvan mine, in Proceedings 33rd US rock mechanics symposium. Santa Fe. Balkema, Rotterdam, pp. 491-500. 
Stacey, T.R. and Page, C.H. (1986) Practical Handbook for Underground Rock Mechanics. Trans Tech Publications. van Aswegen, G. (2008) Ortlepp Shears - Dynamic Brittle Shears of South African Gold Mines, in Proceedings First Southern Hemisphere International Rock Mechanics Symposium, Y. Potvin, J. Carter, A. Dyskin, R. Jeffrey (eds), Australian Centre for Geomechanics, Perth, Australia, Volume 2, pp. 111-119.

Von Kimmelmann, M.R., Hyde, B. and Madgwick, R.J. (1984) The use of computer applications at BCL limited in planning pillar extraction and design of mining layouts, in Proceedings ISRM symposium design and performance of underground excavations, Geotechnical Society, London, pp. 53-63.

Wagner, H. and Madden, B.J. (1984) Fifteen years' experience with the design of coal pillars in shallow South African collieries: an evaluation of the performance of the design procedures and recent improvements, in Proceedings ISRM Symposium on Design and Performance of Underground Excavations, Cambridge, pp. 391-399.

York, G. and Canbulat, I. (1998) Scale effect, critical rock mass strength and pillar systems design. Journal S. Afr. Inst. Min. Metall., 98(1): pp. 23-37. 